\title{
Circadian rhythm of VEGF expression in the liver of hepatectomized tumor bearing mice
}

\author{
Laura Andrini, Marcela García*, Ana María Inda and Ana Lía Errecalde \\ Cátedra de Citología, Histología y Embriología "A”. Facultad de Ciencias Médicas. Universidad \\ Nacional de La Plata, Calle 60 y 120 (1900) La Plata. Bs. As. Argentina
}

(Received 6 January 2009; final version received 3 March 2009)

\begin{abstract}
In this study we analyzed VEGF-C expression in regenerating liver (after partial hepactectomy) of ES2 hepatocellular carcinoma bearing mice, throughout one complete circadian cycle. The animals were sacrificed every $4 \mathrm{~h}$ throughout one complete circadian cycle from 26 to $50 \mathrm{~h}$ post-hepatectomy. Tumor samples were processed for immunohistochemistry. The expression of VEGF was assessed according to the percentage of immunoreactive cells in a total of 1000 cells (quantitative analysis). The results show that controls and tumor bearing mice have statistical differences at all analysed time points, but the maximun value of VEGF expression of treated animals is significantly higher $(p<0.01)$ than the control group. We can conclude that when a partial hepatectomy is made with the purpose of eradicating a hepatic tumor, the presence of possible metastasis could release factors related with cellular proliferation that could increase the possibilities of tumoral recidives.
\end{abstract}

Keywords: liver; VEGF; hepatocellular carcinoma; circadian rhythms; mouse

\section{Introduction}

VEGF is the most potent angiogenic factor known (Mattern et al. 1996). It is a glycoprotein with angiogenic, mitogenic and vascular permeability enhancing activity in endothelial cells (Mineo et al. 2004). The VEGF family includes VEGF-A, B, C, D, E, F as well as PLGF (placenta growth factor) (Shibuya 2008). In humans, VEGF-C and D activates VEGFR-2 and VEGFR-3 receptors, both of which are essential for vascular development (Cao et al. 1998).

On the other hand, tumor growth and evolution is a complex phenomenon controlled by an intricate pattern of competing processes (Perez de Castro et al. 2007). Previous studies have demonstrated that many cellular neoplastic populations have circadian variations in their mitotic activity (MA), such as primary human and murine tumors (Colombo et al. 2000), including mammary carcinomas (Echave Llanos and Badrán 1963), hepatomas and hepatocellular carcinomas (Barbeito et al. 1993, 1995). Circadian variations in the synthesis of DNA (DNAs) of some hepatomas and hepatocellular carcinomas have also been found (Nash and Echave Llanos 1971; Garcia et al. 2008). In some cases, the observed rhythm was similar to that of the original

*Corresponding author. Email: mngarcia@med.unlp.edu.ar 
cellular population (Barbeito et al. 1995), but some undifferentiated hepatocellular carcinomas did not have any mitotic circadian rhythm (Moreno et al. 1985).

Moreover, when a partial hepatectomy is performed on rodents, a compensatory hyperplasia of the remnant lobes is observed (Fausto et al. 2006). Particularly in mice, and under controlled conditions of light-dark standardization, this process involves a circadian rhythm in the MA and DNAs, on the hepatocyte cell population. The partial hepatectomy produces significant increases in plasma levels of a number of potential signals: Hepatocyte Growth Factor (HGF), Insulin-Like Growth Factor (IGF), Transforming Growth Factor $\alpha$ and $\beta$ (TGF $\alpha$ and $\beta$ ), Fibroblastic Growth Factor (FGF), and others. Some of these growth factors can "cross-talk" between the growing tumor and the regenerating liver (Michelson and Leith 1995). There are numerous previous studies that investigated the effect of hepatectomy on the proliferation and growth of the different tumors (Lee 1971; Ono et al. 1986; Hanigan et al. 1990; Sun et al. 1996; Altum and Olzapan 2004). This fact is very important not only in the cellular biology area, but also in clinical oncology, because hepatectomy is the primary treatment for hepatic tumors (Wood and Hrushesky 1996).

These previous studies suggest that tumor-based signals, acting upon the tumor bed stroma, could mimic normal signaling, and, among others things, produce a reciprocal cue beneficial to the proliferating tumor cells (West and van de Rjin 2007). The interaction between tumor cells and their supportive stroma play a crucial role in tumor development and progression (Zhang et al. 2006), in which the angiogenesis is the essential process since solid tumors cannot growth beyond $1-2 \mathrm{~mm}$ in diameter without neovascularization (Folkman et al. 1981).

We analyzed VEGF-C expression in regenerating liver (after partial hepactectomy) of ES2 hepatocellular carcinoma bearing mice throughout one complete circadian cycle.

\section{Materials and methods}

\section{Animals}

For these experiments, we used adult (90 days old) male $\mathrm{C} 3 \mathrm{H} / \mathrm{S}$-strain mice. Conditions concerning animal management fully respected the policy and mandates of the Guide for the Care and Use of Laboratory Animal Research of the National Research Council. They were subjected to the following standardization conditions: water and food were available ad libitum, ambient temperature was maintained at $22 \pm 2{ }^{\circ} \mathrm{C}$, alternating light and dark periods were restricted to $12 \mathrm{~h}$ each with illumination by fluorescent lamps beginning at 06:00 $\mathrm{h}$.

\section{Determination of VEGF expression}

Deparaffinized and rehydrated sections were microwaved for 10 minutes in buffer citrate at $\mathrm{pH}$ 6. Endogenous peroxidase was blocked for 20 minutes, the primary antibody against VEGF-C (mouse monoclonal antibody; Santa Cruz Biotechnology, California, USA 1:100 dilution). Bound primary antibody was detected by Envision Systen (Dako) for 30 minutes and the reaction was developed using diaminobenzidine, and counter-staining with Mayer hematoxylin. The positive control was a section of liver that had previously been shown to have a high VEGF content, by immunohistochemistry. VEGF staining was seen in the hepatocyte cell cytoplasm. 
The expression of VEGF was assessed acording to the percentage of immunoreactive cells in a total of 1000 cells (quantitative analysis). There was $>95 \%$ agreement between the two observers for the VEGF evaluation. A final score was determined by consensus after re-examination.

\section{Experimental groups}

The animals were divided in two experimental groups: Group I (control, hepatectomized animals): these mice were all subjected to a partial (ca. $70 \%$ ) resection of the liver at 10:00 h, with the constituent lots being subsequently sacrificed every $4 \mathrm{~h}$ beginning at $12: 00 \mathrm{~h}$ on the next day of surgery ( $26 \mathrm{~h}$ posthepatectomy) and continuing until 12:00 h on the second day after surgery $(50 \mathrm{~h}$ post-hepatectomy). Group II (hepatectomized and tumor bearing animals): after an appropriate period of synchronization (15 days), about $70 \mathrm{mg}$ of the $\mathrm{C} 3 \mathrm{H} / \mathrm{S}$ histocompatible ES2a hepatoma was grafted into the subcutaneous tissue of each animal's flank. This rapidly growing undifferentiated hepatocellular carcinoma is maintained by subcutaneous serial transplant in male mice. The graft-bearing animals, subsequently divided into lots of 5-6 mice each, were then housed for further two weeks under standardization conditions before the lots were separated. All animals were subjected to a partial (ca. 70\%) resection of the liver and sacrificed at every $4 \mathrm{~h}$, under the same conditions and hours as the first group.

\section{Statistical analysis}

The statistical analysis of VEGF expression was performed using ANOVA and Tukey's post-comparison test. The marked hepatocytes were recorded by counting 70 areas and the total nuclei every 10 areas. The results were expressed as a percentage of marked cells.

\section{Results}

As seen in Table 1 and Figure 1, both groups have statistical differences in all analysed time points, but the tumor bearing animals present the maximum value of VEGF expression at $16 / 30 \mathrm{~h}$ (hour of day/hours post-hepatectomy) and the minimum at $20 / 34 \mathrm{~h}$, meanwhile the other group shows its maximum value at $08 /$ $46 \mathrm{~h}$ and a minimum at $00 / 38 \mathrm{~h}$.

The maximum value of VEGF expression of tumor bearing animals is significantly higher $(p<0.01)$ than that of control animals.

\section{Discussion}

Liver regeneration is not a simple response to one growth factor, but rather a delicate and complex interplay of many cellular events. The ES2 hepatocellular carcinoma secretes factors that stimulate the expression of VEGF by hepatocytes in regenerating liver. Relevant factors might include FGF-7, Keratinocyte Growth Factor (KGF), Epidermal Growth Factor (EGF) and TGF- $\alpha$, which exert mitogenic actions on specific cellular populations. In addition, partial hepatectomy in rodents changes the concentrations of substances such as Tumor Necrosis Factor- $\alpha$ (TNF- $\alpha$ ), HGF, TGF- $\alpha$ and TGF- $\beta$, which are involved in cellular proliferation and cause 
Table 1. Daily mean values of VEGF expression of ES2a hepatocellular carcinoma of the two experimental groups.

\begin{tabular}{lcccccc}
\hline Lote & Time point $(\mathrm{h})$ & Control $(\mathrm{X} \pm \mathrm{SE})$ & $n$ & Tumour bearing $(\mathrm{X} \pm \mathrm{SE})$ & $n$ & $p$ \\
\hline 1 & $12 / 26$ & $3.4 \pm 0.6$ & $(5)$ & $4.5 \pm 0.6$ & $(5)$ & $\mathrm{ns}$ \\
2 & $16 / 30$ & $3.7 \pm 0.6$ & $(5)$ & $14.3 \pm 2.1$ & $(5)$ & 0.001 \\
3 & $20 / 34$ & $2.9 \pm 0.5$ & $(5)$ & $5.4 \pm 2.1$ & $5)$ & $\mathrm{ns}$ \\
4 & $00 / 38$ & $3.2 \pm 0.9$ & $(5)$ & $1.7 \pm 0.3$ & $(5)$ & $\mathrm{ns}$ \\
5 & $04 / 42$ & $4 \pm 0.4$ & $(5)$ & $4.4 \pm 1.0$ & $(6)$ & $\mathrm{ns}$ \\
6 & $08 / 46$ & $7.1 \pm 1.0$ & $(6)$ & $3.7 \pm 0.7$ & $(5)$ & 0.05 \\
7 & $12 / 50$ & $3.9 \pm 1.3$ & $(5)$ & $3.0 \pm 0.8$ & $(5)$ & $\mathrm{ns}$ \\
\hline
\end{tabular}

Lotes 2 y $4: p<0.01$.

Lotes 3 y $6: p<0.05$.

h: hour of day/hours post-hepatectomy.

$\mathrm{X}$ : means of the samples.

ES: standard error.

n: number of mice per group.

p: probability.

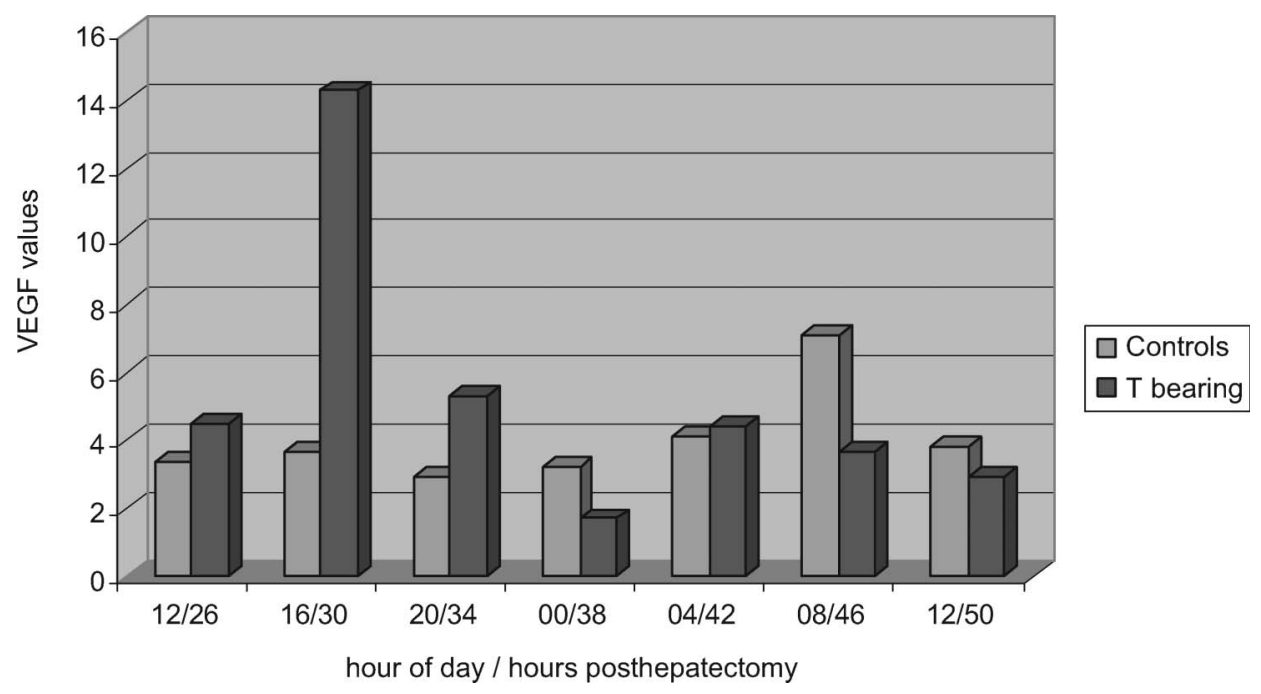

Figure 1. VEGF expression in hepatocytes throughout one circadian rhythm after hepatectomy. Controls: controls mice; $\mathrm{T}$ bearing: tumor bearing mice.

compensatory hyperplasia of the remanent lobes of the liver (Dielh and Rai 1996; Kimura et al. 1997; Michalopoulos and Defrances 1997). Some of these factors produced during the hepatic compensatory hyperplasia can alter tumoral cell proliferation. Moreover, the concentration of a factor can increase in the tumors; for example TGF- $\alpha$ is synthesized by numerous hepatocellular carcinomas in the rat (Perez Tomas et al., 1992).

On the other hand, angiogenesis is a complex process that involves endothelial cell migration, capillary bredding, neovascular remodeling, in addition to endothelial cell proliferation (Karamysheva 2008). The growth of solid tumors like those analyzed in this study needs an adequate vascular network for the supply of oxygen and nutrients, and to remove waste products, although it has been established that 
tumor cell proliferation decreases with increasing distances from the blood vessels (Vartanian et al. 1994; Vermeulen et al. 1996).

As we can see in our study, both groups have circadian variations of VEGF expression in hepatocytes. But the presence of transplanted tumor causes modifications in the intensity and the temporal expression of VEGF in this cellular population. In transplanted animals the VEGF peak appears before, and with higher values, than the control group. Thus we can affirm that ES2 hepatocellular carcinoma increases directly or indirectly with VEGF expression of hepatocytes.

All the foregoing considerations confirm that beyond an experimental design which takes into account factors such as the moment of grafting, the location of the tumor implant and the origin of the neoplasm, it is not possible to make a general statement regarding the effects of host hepatectomy on tumor growth, because these influences will vary according to the nature of each tumor. The production of growth factors on the part of the host and the neoplastic cells themselves will vary among different tumors (Aaronson 1991; Yeh et al. 2006).

We can conclude that when a partial hepatectomy is made with the purpose of eradicating an hepatic tumor, the presence of possible metastasis could release factors related to cellular proliferation and the possibility of tumoral recidives could increase.

\section{References}

Aaronson SA. 1991. Growth factors and cancer. Science. 254:1146-1453.

Altum S, Ozalpan A. 2004. Interactive regeneration of liver and growth of Ehrlich ascites tumor in mice. Biologia Bratislava. 59:375-382.

Barbeito CG, Badrán AF, Moreno FR. 1995. Daily variations in the proliferation of neoplastic hepatocytes from the ES15 tumor. Analecta Veterinaria (in Spanish). 15:35-39.

Barbeito CG, Moreno FR, Badrán AF, Zalduendo MA. 1993. Evolution of mitotic activity of the carcinoma ES14 in a circadian period. Comunicaciones Biológicas (in Spanish). $11: 154$.

Cao Y, Linden O, Farnebo J, Cao R, Eriksson A, Kumar V, et al. 1998. Vascular endothelial growth factor-C induces angiogenesis in vivo. Proc Natl Acad Sci USA. 95:14389-14394.

Colombo LL, Mazzoni EO, Meiss RP. 2000. The time of tumor cell division and death depends on the site of growth. Oncol Rep. 7:1363-1366.

Dielh AM, Rai R. 1996. Regulation of liver regeneration by pro-inflammatory cytokines. J Gastroenterol Hepatol. 11:466-470.

Echave Llanos JM, Badrán AF. 1963. 24-hour rhythm in the mitotic activity of a grafted mammary carcinoma in female $\mathrm{C} 3 \mathrm{H} /$ Mza mice on normal and inverted lighting regimens. J Roy Micr Soc. 82:75-80.

Fausto N, Campbell J, Riehle KJ. 2006. Liver regeneration. Hepatology. 43:545-553.

Folkman J, Watson K, Ingiber D, Hanahan D. 1981. Induction of angiogenesis during the transition from hyperplasia to neoplasia. Nature (Lond). 339:58-61.

Garcia M, Andrini L, Errecalde A, Cerutti R, Barbeito C. 2008. Changes in DNA circadian rythms in a transplantable hepatocellular carcinoma alter and hepatectomy. Biol Rhythm Res. 39:1-11.

Hanigan MH, Winkler ML, Drinkwater NR. 1990. Partial hepatectomy is a promoter of hepatocarcinogenesis in $\mathrm{C} 57 \mathrm{BL} / 6 \mathrm{~J}$ male mice but not in $\mathrm{C} 3 \mathrm{H} / \mathrm{HeJ}$ male mice. Carcinogenesis. 11:589-594.

Karamysheva AF. 2008. Mechanism of angiogenesis. Biochemistry. 73:751-762.

Kimura K, Sakaida I, Terai S, Matsumura Y, Uchida K, Kiwamu O. 1997. Inhibition of tumor necrosis factor - alfa production retards the liver regeneration after partial hepatectomy in rats. Biochem Biophys Res Commun. 231:557.

Lee JC. 1971. Effects of partial hepatectomy in rats on two transplantable hepatomas. Am J Pathol. 65:347-356. 
Mattern J, Koomägi R, Volm M. 1996. Association of VEGF expression with intratumoral microvessel density and tumour cell proliferation in human epidermoid lung carcinoma. Br J Cancer. 73:931-934.

Michalopoulos GK, Defrances MC. 1997. Liver regeneration. Science. 276:60-66.

Michelson S, Leith JT. 1995. Interlocking triads of growth control in tumors. Bull Mathematical Biol. 57:345-366.

Mineo T, Ambrogi V, Baldi A, Rabitti C, Bollero P, Vincenzi B, et al. 2004. Prognostic impact of VEGF, CD31, CD34 and CD105 expression and tumour vessel invasion after radical surgery for IB-II A non-small cell lung cancer. J Clin Pathol. 57:591-597.

Moreno FR, Badrán AF, Echave Llanos JM. 1985. Mitotic activity of a fast and slow growing hepatocarcinomas during liver regeneration in the host. Comunicaciones Biológicas (in Spanish). 4:409-416.

Nash RE, Echave Llanos JM. 1971. Twenty-four hour variations in DNA synthesis of a fastgrowing and a slow-growing hepatoma: DNA synthesis rhythm in hepatomas. J Nat Cancer Inst. 47:1007-1012.

Ono M, Tanaka N, Orita K. 1986. Complete regresion of mouse hepatoma transplanted after partial hepatectomy and the immunological mechanism of such regression. Cancer Res. 46:5049-5053.

Perez de Castro I, de Cárcer G, Malumbres M. 2007. A census of mitotic cancer genes: new insights into tumor cell biology and cancer therapy. Carcinogenesis. 28:899-912.

Perez Tomas R, Mayol X, Cullere X, Ruiz Diaz C, Domingo J. 1992. Transforming growth factor alpha expression in rat experimental hepatocarcinogenesis. Histol Histopathol. $7: 457-462$.

Shibuya Masabumi. 2008. Vascular endothelial growth factor-depend and - independent regulation of angiogenesis. BMB Reports. 278-286.

Sun J, Toshinori I, Zhang F. 1996. Enhancement of tumor growth after partial hepatectomy and blood transfusion. Chung hua Shung Liu Tsa Chic. 18:113-115.

Vartanian RK, Weidner N. 1996. Correlation of intratumoral endothelial cell proliferation with microvessel density (tumor angiogenesis) and tumor cell proliferation in breast carcinoma. Am J Pathol. 144:1188-1194.

Vermeulen P, Gasparini G, Fox SB, Toi M, Martin L, McCulloch P, et al. 1996. Quantification of angiogenesis in solid human tumors: an international consensus on methodology and criteria of evaluation. Eur J Cancer. 32A:2474-2484.

West RB, van de Rjin M. 2007. Experimental approaches to the study of cancer stroma interactions: recent findings suggest a pivotal role for stroma in carcinogenesis. Lab Invest. 87:967-970.

Wood PA, Hrushesky WJM. 1996. Circadian timing of cancer chemotherapy. In Critical reviews in eukariotic gene expression. $2^{\text {nd }}$ ed. Baltimore: Williams and Wilkins. p. 177202.

Yeh ES, Lew BO, Means AR. 2006. The loss of PIN1 deregulates cyclin E and sensitizes mouses embryo fibroblasts to genomic instability. J Biol Chem. 281:241-251.

Zhang L, Zhao Z, Ru G, Ma J. 2006. Correlative studies on uPA mRNA and uPAR mRNA expression with vascular endothelial growth factor, microvessel density, progression and survival time of patiens with gastric cancer. World J Gastroenterol. 12:3970-3976. 